\title{
La identidad cultural y los negocios: Los Gordos de Tepatitlán
}

\author{
Cultural Identity and Business: Los Gordos from Tepatitlán
}

\section{Identidade cultural e negócios: Los Gordos de Tepatitlán}

\author{
Ana Gabriela González Anaya \\ Universidad de Guadalajara, México \\ ana.ganaya@academicos.udg.mx \\ https://orcid.org/0000-0003-4075-1768
}

\section{Resumen}

En este trabajo se presenta un análisis de la historia de Los Gordos, un restaurante de comida típica mexicana cuyo platillo principal es la carne de cerdo que se fríe en un cazo. La historia del restaurante se puede asociar con la de la urbanización del municipio de Tepatitlán, en donde se localiza dicha empresa. Los elementos culturales fueron importantes en el éxito de esta, así como dotaron de elementos identitarios al municipio. El restaurante no era el área fuerte de la empresa, pero fue la que volvió famosos a sus dueños en la región. Se planteó en esta investigación demostrar que existe una relación entre los negocios y la identidad cultural; relacionar la evolución de un negocio con la urbanización de una ciudad media, y delimitar cuáles son las consecuencias del paso de un negocio tradicional a uno más urbanizado en una comunidad que intenta resistirse al cambio cultural. A partir de tres entrevistas a profundidad hechas a los nuevos dueños, así como a empleados que laboraron desde la década de los 60 en el negocio, es que se presentan los resultados de este trabajo. A ello se suma un análisis de la importancia que tiene la gastronomía como elemento cultural de un territorio. La explicación de la identidad cultural que evoluciona tiene características propias, distinguibles con respecto a otras. La religión, ruralidad y economía son elementos que aparecen en este 


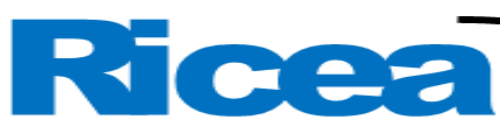

REVISTA IBEROAMERICANA DE CONTADURÍA, ECONOMÍA Y ADMINISTRACIÓN

ISSN= $2007-9907$

trabajo, además de la cultura, como influencias para el éxito y desarrollo tanto del restaurante que se estudió como del municipio en el que se encuentra.

Palabras clave: identidad cultural, negocio, restaurante.

\section{Abstract}

In this text it is presented the analysis of the history of Los Gordos, a Mexican food restaurant whose main dish is fried pork made in a cazo (a huge copper pot used for this dish). The history of the restaurant can be associated with that of the urbanization of the city of Tepatitlán, where this company is located. Cultural elements were also important in its success, as well as providing identity elements to the place. The restaurant was not the principal area of the company, but it was the one that made its owners famous in the region. In this work it is presented an analysis with three objectives: to demonstrate the relation between business and cultural identity; to link the evolution of a business with a small city urbanization process, and to define what are the consequences of going from a traditional business to a more urbanized one in a community that tries to resist the cultural changes. Based on in-depth interviews made to the new owners, as well as with employees who have worked in the business since the 60's, the results of this paper are presented. There is also an analysis of the importance of gastronomy as a cultural element of a territory. And the explanation of the cultural identity that evolves has its own characteristics. Religion, rurality and economy are other elements presented in this paper, as influences in the success and development of both the restaurant that was studied, and the city in which it is located.

Keywords: cultural identity, business, restaurant.

\section{Resumo}

Este trabalho apresenta uma análise da história de Los Gordos, um restaurante de comida típica mexicana cujo prato principal é o porco frito em uma panela. A história do restaurante pode ser associada à da urbanização do município de Tepatitlán, onde se encontra a empresa. Os elementos culturais foram importantes para o seu sucesso, além de fornecerem elementos de identidade ao município. O restaurante não era o forte da empresa, mas era o que fazia a fama dos seus proprietários na região. Foi proposto nesta pesquisa demonstrar que existe uma relação entre empresa e identidade cultural; relacionar a evolução de um negócio com a 


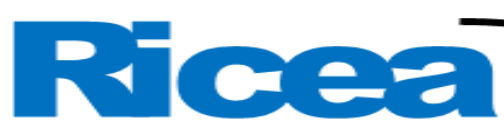

REVISTA IBEROAMERICANA DE CONTADURÍA, ECONOMÍA Y ADMINISTRACIÓN

ISSN= $2007-9907$

urbanização de uma cidade média e definir as consequências da transição de um negócio tradicional para outro mais urbanizado em uma comunidade que tenta resistir às mudanças culturais. Os resultados deste trabalho são apresentados a partir de três entrevistas em profundidade com os novos proprietários, bem como com funcionários que trabalham na empresa desde a década de 1960. Soma-se a isso uma análise da importância da gastronomia como elemento cultural de um território. A explicação em evolução da identidade cultural tem características próprias, distinguíveis das outras. Religião, ruralidade e economia são elementos que aparecem neste trabalho, além da cultura, como influências para o sucesso e desenvolvimento tanto do restaurante estudado quanto do município em que está inserido.

Palavras-chave: identidade cultural, negócios, restaurante.

Fecha Recepción: Julio 2020 Fecha Aceptación: Diciembre 2020

\section{Introducción}

Con este trabajo se pretende no solo narrar la historia de un negocio famoso en una región localizada en el occidente de México, sino también explicar cómo es que hay una relación entre territorio, identidad y los negocios considerados tradicionales o propios de una comunidad —como ejemplo se puede revisar a Castro (2020)—. El negocio, en este caso, es el restaurante de Los Gordos, de Tepatitlán, Jalisco, famoso por la venta de carnitas, un platillo de carne de cerdo que se fríe en un cazo (Los Gordos, 2020). Dicha preparación del alimento se convirtió en un símbolo del municipio y sigue siendo uno de los más reconocidos a nivel regional y estatal desde hace varias décadas.

El objetivo principal de la investigación era el de describir la historia de un negocio reconocido a nivel nacional. No obstante, entre los objetivos específicos, el planteamiento fue dirigido a demostrar que existe una relación entre los negocios y las comunidades a las que pertenecen, así como a los cambios que existen en las mismas. Dichos objetivos son los siguientes: 1) demostrar que existe una relación entre los negocios y la identidad cultural (a partir de un análisis cualitativo); 2) relacionar la evolución de un negocio con la urbanización de una ciudad media, y 3) delimitar las consecuencias del cambio de un negocio tradicional a uno moderno. 


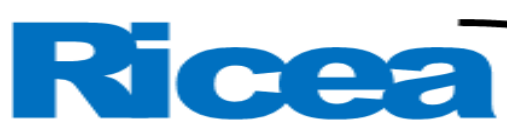

REVISTA IBEROAMERICANA DE CONTADURÍA, ECONOMÍA Y ADMINISTRACIÓN

ISSN $=2007-9907$

La naturaleza de este trabajo es de carácter cualitativo. El interés se centra en los significados. Es imposible medir cómo es que un negocio es parte de la identidad de las personas, pero a partir de los relatos sí puede entreverse una apropiación de la historia, tradiciones e incorporación de un negocio como un elemento identitario para una comunidad. Para obtener esta información, fue necesario recurrir a la entrevista a profundidad como la técnica principal. Para ello, se hizo una entrevista en distintas sesiones con los dueños actuales y con dos de los trabajadores que comenzaron a laborar en el restaurante desde la década de los 60.

La pretensión era obtener de ellos un relato de cómo la modernidad llega a sustituir a la tradición y puede afectar a negocios como al que aquí se alude, que en un tiempo no solo fueron rentables, sino que, en este caso en concreto, además era uno de los que más ingresos generaba y de mayor popularidad gozaba en la región, sin olvidar el gran número de personas que empleaba. Sus anécdotas, recuerdos y afirmaciones no solo conformaron la historia del restaurante, sino que también fueron relacionando esta historia particular con Tepatitlán, ciudad en donde se ubica.

A partir de diversas fuentes textuales se analiza la forma en la que la identidad cultural se hace manifiesta y evoluciona a la par de un negocio. La identidad toma así elementos de la tradición (Castro, 2020; Giménez, 2016): ser tepatitlense implica saber de carnitas y haberlas consumido en distintas ocasiones. Ser de la región conlleva el saber cómo era la venta de estas carnitas, narrar cómo es que acudían al consumo de estas y la manera en la que, sentarse a comer tacos de carne de cerdo, sin plato, sin mesa y sin una silla, podía ser una experiencia que aún hay quienes recuerdan con nostalgia.

\section{Territorio, identidad y urbanización}

De acuerdo con el Instituto Nacional de Estadística y Geografía [Inegi] (2019), una población es considerada como rural cuando cuenta con menos de 2500 habitantes. Esto deja claro por qué se pasó de $43 \%$ de población mexicana que se localizaba en ciudades en los años 50 a $78 \%$ en 2010. No obstante, esta definición no es suficiente para lo que se pretende revisar en este documento.

Es importante hacerse algunas preguntas: ¿cómo saber cuándo se pasa de campo a ciudad?, ¿en qué momento lo rural se convierte en urbano?, y, en lo que atañe más particularmente a este trabajo, ¿qué pasa con lo tradicional una vez que las pequeñas 


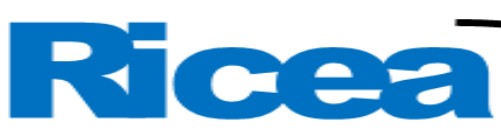

REVISTA IBEROAMERICANA DE CONTADURÍA, ECONOMÍA Y ADMINISTRACIÓN

ISSN $=2007-9907$

poblaciones crecen? Es posible que económicamente haya un reconocimiento del paso de lo rural a lo urbano a partir de servicios sociales y de infraestructura que determinan la diferencia entre unos y otros, como lo señala Franco (2016): la electricidad, salud, telefonía, caminos, saneamiento y los circuitos de actividad productiva, entre otros. Sin embargo, podemos descubrir que existen sociedades que se resisten al cambio, como la alteña. Podrá contar con estos servicios, pero la población mantiene tradiciones muy arraigadas y que parecieran no cambiar con el paso de los años (Fábregas, 2019).

Para algunos autores, como Aguilar (1992), el énfasis debe estar en el proceso de cambio del campo a la ciudad; para otros, como Pradilla (2002), el capitalismo se ha expandido de manera tal que la estructura rural se convierte en urbana.

La agricultura ha definido lo urbano a partir de la especialización: genera los alimentos y materias primas que la ciudad requiere, mientras que esta última ofrece bienes y servicios al campo; así, se complementan ambos (Méndez, 2005; Ramírez, 2005). La migración entre campo y ciudad lleva a que en los espacios rurales puedan desarrollarse actividades terciarias. Así como ciudades pequeñas tienen habitantes que se desplazan a la ciudad para el consumo, las pequeñas poblaciones toman a las ciudades que se encuentran en este punto intermedio — ciudades rurales, les llama Méndez (2005) - como un punto de encuentro y donde pueden hacer uso de bienes y servicios en una escala menor que como se hace en las metrópolis.

Para Arias (2005), las nuevas ruralidades implican cambios económicos, donde la agricultura no se convierte en la actividad económica en la que se basa el progreso de la localidad. La destreza de los habitantes hace que puedan elaborar trayectorias nuevas en las áreas de trabajo. Podemos pensar que es el caso de Tepatitlán, que en la década de los 60 comienza a desarrollarse en la avicultura, con ganaderos y agricultores que empezaron a apostar por la producción del huevo y la venta de gallinas y carne de pollo.

Las nuevas industrias llevaron a cambiar los mercados y, en términos de expansión, a ir más allá del ámbito local o regional, caso que sucedió especialmente con Tepatitlán y Lagos de Moreno (Cabrales, 1991). La población fue aumentando y la base económica se mantiene relacionada con la ganadería (con producción de huevo, leche y carne).

Este cambio en la población, al que Patricia Arias (2005) denomina como nueva ruralidad, depende de la especialización económica, que lleva a dos posibles escenarios: 1) la especialización se convierte en la actividad económica de la población y todas las 


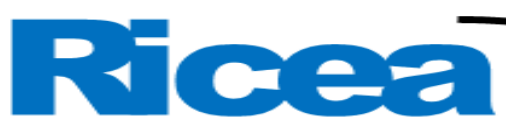

REVISTA IBEROAMERICANA DE CONTADURÍA, ECONOMÍA Y ADMINISTRACIÓN

ISSN= $2007-9907$

actividades giran en torno a ella y 2) la maquila se vuelve una actividad donde laboran principalmente las mujeres.

Esta urbanización conlleva a la llegada de nuevas demandas, especialmente de servicios (Ramírez, 2005). Una de las actividades de este campo se relaciona con la gastronomía y el sector restaurantero. Los principales beneficiados por estos servicios fueron los habitantes de poblaciones cercanas más pequeñas, tales como Acatic, Capilla de Guadalupe, San José de Gracia, Mezcala y Pegueros (Cabrales, 1992).

Hay quienes definen lo rural no solo como el campo, lo agrícola, el lugar carente de bienes y servicios, así como el espacio donde el ruido, las multitudes, la delincuencia y contaminación estarían ausentes, como lo señala Méndez (2005); lo rural también incluiría lo tradicional. Las industrias se concentrarían en la ciudad, así como proveerían de lugares para la comercialización. No obstante, es también en las pequeñas localidades donde se ofrecen espacios para comercializar bienes y servicios y donde lo tradicional puede ser un negocio exitoso. La urbanización no ocurre solo en territorios como las cabeceras municipales, y que influyen en la dinámica de poblaciones rurales que les rodean (Ramírez, 2005). Por ello, los cambios ocurridos en Tepatitlán en las últimas décadas del siglo XX tuvieron un impacto también en otros municipios, tema que no se desarrollará en este trabajo, pero que vale la pena señalarse para posibles estudios posteriores.

La comunidad deja atrás su vida rural para pasar a la urbanidad a partir de los cambios en su infraestructura — por ejemplo, la construcción de las autopistas que conectaron de manera más rápida y eficiente a los municipios - como una forma de lograr el crecimiento económico y desarrollo poblacional (Ramírez, 2005). Esta búsqueda de la urbanización, de diferenciarse del campo, sí llevó a un proceso de mejoras en algunos aspectos. No obstante, negocios como Los Gordos se vieron golpeados por estos cambios.

Tepatitlán, ciudad en la que se sitúa el negocio que se analiza en este trabajo, se localiza en la región Altos Sur del estado de Jalisco, al occidente de México. La ciudad contaba con una población, hacia finales de la segunda década del siglo XXI, de 136000 habitantes; de este total, 100000 se concentraban en la cabecera. Es importante destacar que se encuentra a 70 kilómetros de Guadalajara, a una distancia similar de San Juan de los Lagos y poco menos de 120 kilómetros de Lagos de Moreno. Es un municipio que cuenta con más de 18000 propiedades privadas rurales (Inegi, 2019). 


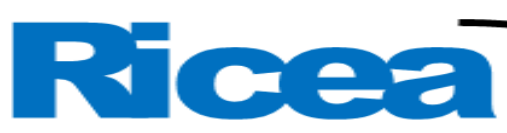

REVISTA IBEROAMERICANA DE CONTADURÍA, ECONOMÍA Y ADMINISTRACIÓN

ISSN $=2007-9907$

Actualmente, Tepatitlán tiene una economía fuertemente orientada al comercio, especialmente tiendas de abarrotes o venta de alimentos (44.9\%), servicios (44.8\%) e industrias (10.3\%); y tan solo un porcentaje mínimo está orientado a la agricultura (apenas $0.1 \%$ ) (Instituto de Información Estadística y Geográfica de Jalisco [IIEG], 2020; Martínez, 2016). Es un municipio cuya población se caracteriza, tal y como lo señalaba Fábregas (2019), por ser sumamente trabajadora, orgullosa de su trabajo, que proviene de una tierra que es muy difícil de trabajar.

Ahora, cuando se habla de región, no solo se centra la definición en el territorio, sino también en lo identitario, aquello que distingue a pobladores de una y otra región. "El territorio sería el espacio apropiado y valorizado — simbólica y/o instrumentalmente - por los grupos humanos" (Giménez, 1999, p. 27). Y de acuerdo con el propio Giménez (1999), se alcanzan a entrever tres tipos de territorios: los identitarios, entre los que pueden estar pueblos, barrios, ciudades pequeñas y otros más amplios como los Estados nación; los territorios relacionados con la sociabilidad, y los territorios culturales, que tienen que ver con la apropiación simbólica del espacio.

El territorio brindará un marco de referencia a sus pobladores. González (1997) señala que los hispanohablantes entendemos a la región como un lugar más pequeño que un reino o república. Además, la gente muy fácilmente puede distinguir entre región, terruño y tierra. El territorio o la tierra sería de donde la persona proviene, implica una denominación espacial con la que sienten un vínculo, un vínculo entre hombre y suelo (González, 1997).

Aquí valdría la pena retomar nuevamente a Giménez (1999), quien sugiere que los habitantes podrán "abandonar físicamente un territorio, sin perder la referencia simbólica y subjetiva al mismo, a través de la comunicación a distancia, la memoria, el recuerdo y la nostalgia" (p. 102). Y este apego surge también por la interiorización de ciertos elementos simbólicos que promueven el sentimiento de pertenencia, que lo diferencian de otros. Uno de estos elementos es la cultura y sus símbolos. La gastronomía del territorio pasa a jugar un papel importante. Demuestra una relación entre alimento y cultura, la forma de cocinar y expresa, por medio de la comida, a la cultura misma (Castro, 2020).

El espacio geográfico se queda corto cuando hablamos de territorio. El territorio es a la vez un objeto de representación y de apego. Dota al individuo del sentimiento de pertenencia, ya que los sujetos interiorizan este espacio como parte de su sistema cultural (Giménez, 2016). Por ello podemos encontrar a migrantes que, a pesar de la distancia, traen 


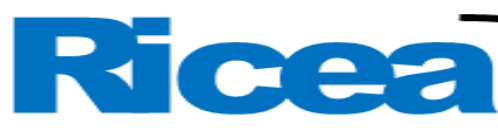

REVISTA IBEROAMERICANA DE CONTADURÍA, ECONOMÍA Y ADMINISTRACIÓN

$15 S N=2007-9907$

consigo su territorio: lo manifiestan en lo que comen, cómo visten, cómo hablan, las tradiciones que siguen y demás.

Así, se encuentra una territorialidad externa, delimitada por la geografía y políticas, y una interna, invisible y subjetiva. Es posible que exista una desterritorialización física, pero ello no implica que los sujetos pierdan su territorio como una referencia simbólica, la memoria o los recuerdos. Entonces, las identidades regionales se van conformando cuando se incorporan símbolos y valores de los sujetos a la región. Y a la vez, la imagen de esta región y todos sus símbolos y significados son interiorizados por los sujetos (Giménez, 2016).

Llegado a este punto es necesario retomar las "matrias" que Luis González propuso (1997). Estas son las microrregiones culturales, los pequeños mundos, en los que hay “sociedades de interconocimiento". Estas regiones tienen su propia historia; la delimitación no será, por lo tanto, solamente espacial, implicará también un periodo de tiempo. En este trabajo se habla del desarrollo de un negocio, pero, a su vez, se liga a este con la historia y tradición de un espacio geográfico, especialmente entre las décadas de los 60 y 90.

Las matrias son aquellas "patriecitas” (González, 1997, p. 170) que cuentan con particularidades; minisociedades donde los municipios, pueblos y terruños tienen características objetivas. Para Luis González (1997), son pequeños mundos que recuerdan a la madre por su amparo, que va más allá del nacimiento. Tal vez sea difícil comprender el término teóricamente, pero si a cualquier mexicano se le pregunta por su origen muy probablemente nos hablaría de su matria. Más allá del municipio, región o localidad a la que se refiera, el término alude al territorio - geográficamente delimitado o no- por el que un individuo siente más apego. Implicará también a las tradiciones, al aspecto emocional, a los valores propios y las costumbres.

Se considera, entonces, a la cabecera de Tepatitlán como una de estas matrias, ya que es una población más pequeña (si la comparamos con la dimensión de la región alteña o el estado de Jalisco) con denominadores comunes, algunos de los cuales son exclusivos y algunos otros los comparten con más alteños. Tepatitlán se conforma de pobladores fuertemente conservadores, católicos, apegados a las tradiciones, como los demás alteños. Son personas de trabajo, también, orgullosos de lo que son y lo que hacen, que viven de su labor en el campo, nuevamente, como el resto de los alteños. No obstante, se convirtió en un centro importante con la llegada de los autobuses, con su rápido desarrollo económico y con símbolos de los que sus habitantes se apropiaron y de los que, por supuesto, se sienten 


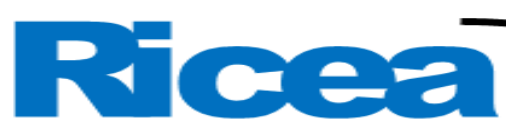

REVISTA IBEROAMERICANA DE CONTADURÍA, ECONOMÍA Y ADMINISTRACIÓN

$15 S N=2007-9907$

sumamente orgullosos. Algunos de estos símbolos serían el Señor de la Misericordia (una imagen que desde hace más de 100 años es fuente de devoción para los tepatitlenses), los personajes que nacieron en esta población y que han destacado por su labor y vidas ejemplares, así como símbolos más tangibles, como podrían ser las carnitas, un platillo que se convirtió en símbolo de esta localidad y por el que es reconocida en otros espacios geográficos.

\section{La gastronomía y la identidad cultural}

La gastronomía cumple, entre varias funciones, la de ser un referente cultural, al ser parte de un territorio, en donde sus actividades no implican solamente la producción y venta de alimentos. Existen elementos culturales alrededor de los alimentos, implica a personas como los productores y consumidores (Castellón y Fontecha, 2018). En este trabajo se pretende mostrar cómo es que la gastronomía y el desarrollo de un negocio enfocado en el servicio restaurantero dotó a la comunidad de un elemento que le identifica con respecto de otras. Se convirtió en parte de la tradición y de la población misma. Así pues, la gastronomía y el ejercicio gastronómico van más allá de la venta de productos alimenticios, porque conlleva implicaciones culturales, sociales, históricas y económicas por supuesto.

Torres, Madrid de Zito y Santoni (2004) explican que las comidas que son ingeridas por individuos de una comunidad, sin importar su lugar en la escala social, se vuelven en símbolos de autorreferenciación o autoidentificación. Todos los miembros de dicha comunidad se apropian de ellos y los convierten en referentes, se convierten en emblemas de su identidad. Tal es el caso de las carnitas en Tepatitlán, son un platillo típico, cuya venta data desde hace varias décadas y que ha adquirido una gran importancia al convertirse en un símbolo de la ciudad.

La identidad cultural incluye las creencias, valores y costumbres de lo colectivo. La gastronomía forma parte de esta identidad al ser uno de los símbolos que se transmiten por generaciones y que se mantienen dentro del grupo. El reconocimiento al producto, a la historia de este, a los elementos que convergen en torno a él, son características que en el territorio evocan a la comunidad misma (Castellón y Fontecha, 2018).

La gastronomía se convierte en un símbolo de lo que arraiga a los hombres a una cultura determinada. Más allá de ingerir los alimentos, es una transmisión cultural. Incluye aspectos como el clima, la lengua, la historia (Fusté, 2016). En el caso de este trabajo, incluso 


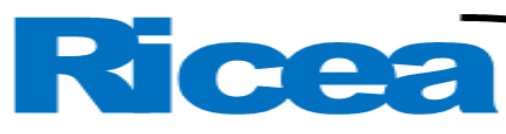

REVISTA IBEROAMERICANA DE CONTADURÍA, ECONOMÍA Y ADMINISTRACIÓN

ISSN= $2007-9907$

el elemento religioso ocupa un papel importante. El consumo de carnitas se convirtió en uno de los ritos que formaba parte del camino de los peregrinos.

Palomar (2005) señala que hay una apropiación simbólica que está implicada en la identidad, hay elementos que se suman para conformarla. Se podría pensar que la comida es uno de estos elementos. Sin embargo, al analizar la historia de Los Gordos, no se trata solamente de un alimento; era la llegada de los camiones, encontrarse a la mitad del camino hacia una peregrinación o de regreso a casa. Sentarse en la banqueta, comer sin utilizar platos o cubiertos. No era solo el sabor de las carnitas, sino todo lo que estaba alrededor del acto de saborearlas. Por ello aún podemos encontrar personas a las que les genera nostalgia el recuerdo de este negocio, y que, a pesar de ello, no acuden a comprar carnitas en el restaurante que aún lleva este nombre, que continúa con la receta y, por lo tanto, con el mismo sabor. El platillo podría ser entonces el pretexto: en realidad la manera de consumirlo era lo que se volvió tradicional.

\section{Resultados: el negocio de las carnitas de Los Gordos}

La historia de Los Gordos comienza con los hermanos Antonio y José Gutiérrez Villarroel. Su trabajo giraba en torno al criadero y venta de carne de cerdo. En Tepatitlán, ciudad en donde se habían establecido, tenían un pequeño obrador, en donde podían sacrificar y procesar a estos animales. El pequeño espacio que tenían no era suficiente para llevar a cabo todas sus actividades, por lo que lo fueron ampliando hasta convertirse en los dueños de una empacadora.

Comercializaban con piernas de cerdo, y comenzaron a trabajar en la elaboración de otros productos, tales como el chicharrón, la manteca, el chorizo y las carnitas. Estas últimas fueron las que les trajeron fama en este municipio y también fuera de él. Don Pepe y don Toño, como les conocían sus empleados y gente del pueblo, aprendieron la receta de su padre, quien era originario de la Ciudad de México. A su vez, este la aprendió de su padre, que era cubano. Las carnitas de Los Gordos fueron una novedad en la región aunque no implicaron una receta o forma de cocinar que se llevara a cabo exclusivamente por los dueños de este negocio, por ejemplo, las carnitas de Michoacán se hacen con el mismo estilo que las de Tepatitlán. Si la receta es similar, si la forma de freírlas también, ¿qué es lo que hizo a estas carnitas tan famosas? y ¿por qué se convirtieron en un símbolo que forma parte de la identidad cultural de los tepatitlenses? 


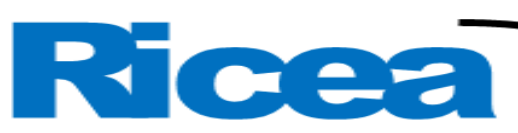

REVISTA IBEROAMERICANA DE CONTADURÍA, ECONOMÍA Y ADMINISTRACIÓN

ISSN $=2007-9907$

Una explicación sobre ello la da el municipio. En su historia oficial se señala que desde el siglo XVII Tepatitlán tenía la comercialización de carne de res y cerdo como una de sus fuentes de economía, la carne se hacía llegar a las empresas mineras de Guanajuato, Zacatecas y San Luis Potosí. La de res, hecha cecina, mientras que la de cerdo se preparaba en carnitas, friéndolas para librar de toda humedad a la carne. La receta se pasaba entonces de generación en generación, y así llegó hasta la época actual. Esta explicación contrasta con la dada por los dueños de Los Gordos, quienes aprendieron la receta de los hermanos Villarroel, que, como ya se señaló en líneas anteriores, explicaron haberla heredado de su abuelo cubano.

Atribuir la receta a un origen cubano no elimina la posibilidad de que un modo de preparación fuera pasado por las generaciones a lo largo de tres siglos. No obstante, la fama la tuvo la preparación de Los Gordos. Pero, como explico más adelante, no es solamente la preparación de este platillo, hay otros elementos que colaboraron a la conformación de este símbolo del municipio.

Además de las carnitas, hay otras cosas para destacar. El nombre de Los Gordos proviene de la condición física de don Pepe y don Toño, ambos — de acuerdo con lo relatado en las entrevistas hechas a sus trabajadores y quienes los conocieron cuando aún vivíanpesaban más de 100 kilos. Esta característica física se convirtió en algo que los identificó, no solo entre la población, sino de forma legal: el nombre se convirtió en su razón social y en la marca que los convirtió en famosos tanto dentro como fuera de la región alteña.

El negocio fue muy productivo. Durante los años sesenta y setenta, los camiones foráneos llegaban a Tepatitlán como un lugar de paso. Al no existir una central camionera, se estacionaban en la plaza de Armas, al lado de la parroquia de San Francisco de Asís, la más importante de la población. El restaurante de Los Gordos se ubicaba alrededor de dicha plaza, a un costado de la parroquia, por lo que ubicarlo era fácil para quienes eran ajenos a la población. Los hermanos habían comenzado a trabajar en su obrador en 1963 y cuatro años después establecieron su famoso restaurante. El objetivo principal de su negocio era trabajar la carne de cerdo, por lo que dos años después del restaurante, ya en 1969, pusieron una empacadora que se ubicaba a las afueras de la cabecera del municipio.

Los hermanos eran socios. Don Toño se hizo cargo del restaurante, en el centro de Tepatitlán, y don Pepe de la empacadora. Una vez que el restaurante cambió su local al lado de la empacadora, don Pepe se hizo cargo de este también. Los hermanos comenzaron 


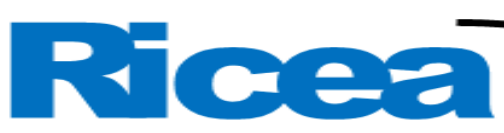

REVISTA IBEROAMERICANA DE CONTADURÍA, ECONOMÍA Y ADMINISTRACIÓN

ISSN $=2007-9907$

haciendo lonchecitos de carnitas y ofreciéndolos por la calle. El platillo de carnitas se volvió popular rápidamente.

Los camiones con destino a León, México, Aguascalientes, Zacatecas, Laredo y Saltillo, entre otros, hacían una pausa en Tepatitlán. Los choferes solían avisar al restaurante antes de comenzar el viaje, para que se pudiera calcular cuántos camiones llegarían y en qué horario lo harían. Uno de los dueños señala: "Nunca hubo temporada baja en el restaurante, pero en algunas fechas había más movilización, como el 27 de julio”. En esa fecha hacían peregrinaciones de Tonalá hasta San Juan de los Lagos para visitar a la Virgen: hasta 67 camiones en un día llegaron a pasar, especialmente cuando el restaurante ya se ubicaba a las orillas de la carretera federal número 80 (donde el tramo que pasa por la cabecera de Tepatitlán se conoce como bulevar Anacleto González Flores).

Los pasajeros bajaban del camión y hacían fila afuera del restaurante para recibir sus tacos de carnitas. Los tacos se entregaban en papel de estraza, no en platos, y eran acompañados solamente por la salsa. "La tortilla quedaba toda mojada, el papel también, pero no les importaba", señala una de las empleadas del restaurante, quien labora allí desde los años 60. También explicaron los trabajadores que la costumbre era comer sentados en la banqueta, pero si eran habitantes de Tepatitlán, pasaban a comer adentro del local.

Durante esa época, las carnitas se hacían con carne que conocemos como tripa, lomo, oreja, buche, trompa y otras. También se freía riñón, nana (ubre de la cerda) y buche. Los tres son difíciles de cocinar, y por esa razón — con excepción del buche- muy raramente se ofrecen en los restaurantes que venden carnitas. "Los cazos se vendían rápidamente, muchas veces, antes de que saliera uno, ya se había vendido", señala una de las trabajadoras.

Apareció la competencia con dos restaurantes que también se mantienen en esta época: El Che y Los Jáuregui. En ambos se hacían carnitas, pero el sabor era distinto. Así, lograban satisfacer a un número más amplio de población. Para los hermanos Villarroel el negocio principal era la empacadora, ya que producían jamón, salchichas, chuletas y tocino, todo lo cual vendían alrededor de todo el país.

Las carnitas habían cobrado fama fuera de la región, este negocio en particular destacaba. Se les señaló durante un tiempo por haber vendido caguama, cosa que desmintieron los trabajadores y dueños en las entrevistas que se realizaron para este trabajo. El restaurante dejó de estar en el centro y se estableció al lado de la empacadora, por la carretera federal 80, en donde aún se localiza. Los camiones ya no llegaban al Centro de 


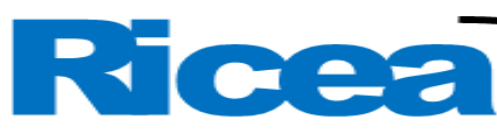

REVISTA IBEROAMERICANA DE CONTADURÍA, ECONOMÍA Y ADMINISTRACIÓN

ISSN= $2007-9907$

Tepatitlán, se les ubicó un espacio a manera de central camionera en las afueras de la cabecera. Si bien el lugar es cercano a donde ahora se encontraba el restaurante, la tradición de ir a las carnitas de Los Gordos fue desapareciendo.

La urbanización del municipio afectó al negocio, tal como se señaló en las entrevistas realizadas. La gente dejó de acudir en masas a comprar las carnitas y el negocio lo resintió grandemente. Además de ello, los hermanos Villarroel ya eran grandes de edad y decidieron dejar el negocio en 1984. Don Pepe anunció que se vendía el restaurante, la empacadora y el rastro a los miembros de la Cámara de la Industria Alimenticia de Jalisco. Se venderían como un paquete, no por separado. Lo compraron 11 socios, pero esta sociedad fue efímera. Al final, el negocio llegó a ser de tres socios, parte de una familia que sigue siendo dueña del restaurante, el obrador y la empacadora. Se traspasaron los negocios y también las recetas. Se mantuvieron y aún hoy se venden los mismos productos: tocino, jamón, salchicha, chorizo, chuleta, chamorro, lomo adobado y las carnitas.

Al restaurante se le incorporó un salón de eventos, se modernizó al primero y esto alejó a la clientela. El restaurante dejó de parecerles tradicional y más bien un lugar para gente de negocios. Los platillos persistían, pero los clientes cambiaron. Muchos de los trabajadores continuaron laborando, a pesar del cambio de dueños, pero otros tantos no quisieron adaptarse a las nuevas propuestas y dejaron sus empleos. La nueva administración había llegado con otra mentalidad sobre cómo hacer negocios, que se asemejaba más a la de las grandes urbes, y se alejaba de lo tradicional.

Aunque las ventas del restaurante no eran tan buenas como cuando se encontraba en el Centro, se mantenían buenas y eran numerosas en algunas fechas en las que había peregrinaciones o fiestas en distintas poblaciones y Tepatitlán, con sus carnitas, seguía siendo una parada obligada.

El cambio más drástico fue cuando se construyó la autopista Zapotlanejo-Lagos de Moreno, que comenzó a utilizarse en la década de los noventa. La carretera federal se convirtió poco a poco en un bulevar y dejó de tener tráfico pesado. El restaurante ya no era una parada usual para peregrinos ni turistas. Las ventas disminuyeron, aunque se han mantenido las recetas y calidad de los platillos ofrecidos.

En las entrevistas uno de los dueños señala que es común encontrar personas que llegan a comer al restaurante porque les recuerda a cuando lo hacían siendo más jóvenes, o que fueron por recomendación de sus padres o abuelos. También, platicar con alguien que es 


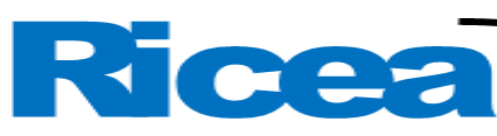

REVISTA IBEROAMERICANA DE CONTADURÍA, ECONOMÍA Y ADMINISTRACIÓN

ISSN $=2007-9907$

ajeno al municipio y mencionarle que se proviene de Tepatitlán, lleva a que se le pregunte por las carnitas de Los Gordos.

Así, hablar de Los Gordos es hablar de carnitas, y hablar de carnitas es hablar de Tepatitlán, como si de una cadena de sinónimos se tratara y una de estas palabras siempre remitiera a las otras dos: Los Gordos, carnitas y Tepa.

Para responder al primer objetivo de esta investigación, es posible definir algunos elementos de relación entre la identidad cultural y los negocios que, si bien están implícitos en los resultados presentados, se resumen a continuación. En primer lugar, el platillo típico (las carnitas) que se volvió propio de la comunidad, independientemente del origen de la receta y modo de preparación. Seguido de ello, se tiene el vínculo con la religión, ya que por motivos religiosos muchas personas ajenas al municipio hacían ahí parada, y una parada en Tepatitlán daba pie a comer carnitas. Además, la estrategia de negocios en la que los choferes de los autobuses convenían con los dueños del restaurante el consumo de los alimentos. Finalmente, cómo es que la tradición no implicaba solo el ingerir los alimentos, sino el lugar en el que se haría, qué tipo de platillos se pedirían para el lugar y cuáles para llevar.

La ciudad evolucionó, de lo rural a lo urbano, haciendo cambios, adoptando el uso de tecnologías, y también modificando las tradiciones. Aunque las personas quisieran seguir comprando en Los Gordos, los autobuses ya no se estacionaban a unos pasos del restaurante. Se perdió la tradición y en cambio se obtuvo mayor facilidad para transportarse fuera del municipio. Por último, el paso del negocio de lo tradicional a lo moderno llevó a un contraste entre la clientela que acudía antes y después de dicho momento. Se perdió esta noción de identificación, se sintió ajeno a la población. De ser un restaurante tradicional para toda la población, se convirtió en uno exclusivo para los empresarios. Y no porque lo plantearan así los dueños, sino que los mismos consumidores así lo fueron decidiendo. 


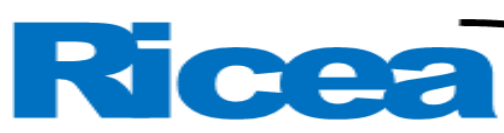

REVISTA IBEROAMERICANA DE CONTADURÍA, ECONOMÍA Y ADMINISTRACIÓN

\section{Discusión}

Se utilizó como ejemplo la historia de Los Gordos para analizar el desarrollo de una población y su proceso de urbanización. La costumbre de llegar en camión a Tepatitlán como una escala en el trayecto, ya fuera por peregrinación o por ir a visitar otros municipios o estados, se convirtió en una tradición tanto para los que no vivían en Tepatitlán como para sus pobladores el recibirlos. Comer carnitas, sentados en una banqueta era una experiencia que los visitantes ansiaban, incluso décadas después lo comentan con cierta nostalgia.

Esta costumbre hizo que en lo particular las carnitas de Los Gordos se volvieran famosas, y que en lo general este platillo se convirtiera en la comida típica de la ciudad, tanto así que aún en la actualidad se pueden encontrar distintos negocios que las ofrecen. Por supuesto, ya no en tacos que la gente come en la calle, ahora siguen el modelo de restaurante que la actualidad propone.

La tradición dotó de identidad a la población, al darle un elemento que la hizo famosa. No obstante, el cambio, la urbanización e incluso la globalización lograron que hubiera mejores comunicaciones y que las demandas fueran otras. Esto trajo la necesidad de crear una central camionera. Y en consecuencia, a partir de la consolidación de esta central, los negocios que rodeaban la plaza de Armas del municipio comenzaron a dejar de recibir tantos consumidores.

La urbanización llegó a trastocar a la pequeña ciudad para convertirla en una más grande, lo moderno sustituyó a lo tradicional, las cosas cambiaron siguiendo la “desterritorialización de las localidades" que señala Giménez (2016): las influencias externas a la localidad llegan a cambiar los modos de vida que se seguían. No obstante, lo tradicional se mantiene en lo comunitario, en la memoria colectiva. Así, podemos encontrar que, aunque la gente ya no acude como antes al restaurante de Los Gordos, el negocio se mantiene porque trae añoranza y recuerdos sobre tiempos que, para algunos, fueron mejores.

Los negocios pueden tener a su favor el convertirse en parte de la identidad de una comunidad. Apropiarse de esta, así como la población lo hace del negocio, lleva a una relación que puede ser benéfica para ambas partes. El compromiso de ayuda entre ambas se vuelve sólido. La publicidad de la empresa recibe un beneficio al que no todas pueden aspirar, y además también existen obligaciones de la institución hacia su comunidad: colaborar con algunos sectores de la sociedad, poner a disposición de otros sus espacios, por ejemplo. 


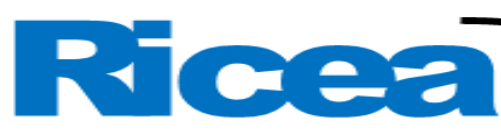

REVISTA IBEROAMERICANA DE CONTADURÍA, ECONOMÍA Y ADMINISTRACIÓN

Es posible profundizar más en el trabajo hecho sobre este negocio como ejemplo de la identidad cultural que surge por las labores que una empresa desarrolla. También se puede pensar en otros negocios, en distintos sectores, que también han dotado de identidad al municipio (como lo son las empresas de avicultores, por ejemplo). No obstante, parece que es difícil hacer una separación entre empresas, ya que el desarrollo de estas ocurrió alrededor de años similares, y han trabajado de manera colectiva. Cosa que no ocurrió con Los Gordos, ya que no se asociaron con otros restaurantes, además de que la venta de la empresa se hizo a personas externas al municipio. Sin embargo, no deja de ser una historia interesante desde el ámbito cultural, gastronómico, económico y, por supuesto, de la historia del municipio.

\section{Conclusiones}

La venta de un platillo podría concebirse como una simple transacción, el cliente paga por un servicio — que sería la preparación del alimento - para su consumo personal. Pero se convierte en un símbolo cuando la preparación lo hace único o lo distingue entre el resto. En el caso de las carnitas de Los Gordos, un sinfín de características hicieron que esta comida se convirtiera en importante y parte de la identidad del municipio de Tepatitlán.

Para otros negocios, basarse en este ejemplo podría llevar a un análisis de la relación que se tiene con la comunidad a la que pertenece. De qué manera ha impactado a la sociedad, y también cómo es que esta incide en la empresa. Explotar esta situación puede llevar a grandes beneficios tanto para el lugar como para el negocio, y también se podrían prever situaciones como la que llevó a Los Gordos a encontrar un impacto negativo a partir de la construcción de la autopista.

No solo fue la preparación de un alimento con una calidad distintiva de ingredientes, el buen sazón de los cocineros, sino también todo lo que implicaba para los visitantes que llegaban al municipio: ir en camión como parte de una peregrinación religiosa, saber que una parada del camino implicaba el consumo de carnitas, las cuales comerían en la banqueta, sosteniendo la comida con sus manos, en un papel de estraza, sin tener un plato. Y de ahí, una vez repuesto energías, poder seguir con su peregrinación.

Para los habitantes de Tepatitlán, siempre orgullosos de su tierra, la fama que este restaurante adquirió se convirtió en una de las características de su población. Es posible entrever cómo es que entonces un negocio se convierte en parte de la identidad. Más allá de 


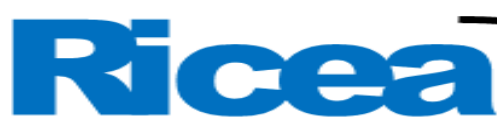

REVISTA IBEROAMERICANA DE CONTADURÍA, ECONOMÍA Y ADMINISTRACIÓN

ISSN $=2007-9907$

una referencia o descripción de su municipio, permite explicar sobre la gastronomía, las costumbres y los cambios ocurridos en la comunidad.

Así, las carnitas de Los Gordos se volvieron en algo que fue más allá de un negocio para ser parte de la identidad cultural de un territorio. Es común encontrar empresas del ramo que se dedican también a la venta de carnitas, pero nunca han igualado la fama ni la nostalgia que conlleva el pensar en las que se vendían a un lado de la plaza del pueblo en los años 60 . Los Gordos son parte de la historia de la población, su gastronomía, sus recuerdos, e incluso una referencia al pasado (especialmente cuando los consumidores hablan de cuando el restaurante se encontraba en el Centro, junto al lugar donde estacionaban los autobuses, lo cual es una plática recurrente en los tepatitlenses de mayor edad).

Los cambios económicos, el crecimiento de la población y la urbanización llevaron a hacer cambios en la estructura del restaurante: adoptar nuevas formas de hacer negocio, otro espacio físico, la venta de los mismos alimentos con otra presentación. Estos cambios, no obstante, aunque puedan parecer ajenos a lo que en un principio fue esta empresa, en realidad no han cambiado su esencia. Se mantienen las recetas, las formas de preparar, pero la sociedad ha dejado de hacer su parada obligada en el restaurante, como parte de su peregrinación. Sin embargo, será muy difícil que estos cambios lleguen a desprender la asociación que se hace entre Tepatitlán, carnitas y Los Gordos. Unos y otros se han otorgado elementos simbólicos, y han compartido historia en las últimas décadas. Así, no importará dónde se coman las carnitas, nunca habrá unas como las de Los Gordos de Tepatitlán. 


\section{Referencias}

Aguilar, A. (1992). Dispersión del proceso urbano. Ciudades, (12), 24-30.

Arias, P. (2005). Nueva ruralidad: antropólogos y geógrafos frente al campo hoy. En Ávila, H. (coord.), Lo urbano-rural, ¿nuevas expresiones territoriales? (pp. 123-160). Cuernavaca, México: Universidad Nacional Autónoma de México.

Cabrales, F. (1991). El proceso de urbanización en los Altos de Jalisco. Anales de Geografía de la Universidad Complutense, (11), 81-107.

Castellón, L. y Fontecha, J. (2018). La gastronomía: una fuente para el desarrollo del turismo y el fortalecimiento de la identidad cultural en Santander. Turismo y Sociedad, (22). 167-193.

Castro, L. (2020). Diseño de interiores como articulador de lenguajes formales identitarios. (Tesis de magíster). Universidad del Azuay, Cuenca.

Fábregas, A. (2019). La formación histórica de una región. Los Altos de Jalisco. México: Centro Universitario de los Altos/Centro Universitario de los Lagos.

Franco, F. (2016). Políticas urbanas y rurales en México. Santiago, Chile: Centro Latinoamericano para el Desarrollo Rural.

Fusté, F. (2016). Los paisajes de la cultura: la gastronomía y el patrimonio culinario. Dixit. 24(1), 4-16.

Giménez, G. (1999). Territorio, cultura e identidades. La región sociocultural. Estudios sobre las Culturas Contemporáneas, 5(9), 25-57.

Giménez, G. (2016). Estudios sobre la cultura y las identidades sociales. Guadalajara, México: ITESO.

González, L. (1997). Invitación a la microhistoria. Obras completas. Tomo IX. México: Editorial Clío.

Instituto de Información Estadística y Geográfica de Jalisco [IIEG]. (2020). Indicadores económicos Tepatitlán de Morelos. Jalisco, México: Instituto de Información Estadística y Geográfica de Jalisco. Recuperado de https://iieg.gob.mx/ns/?s=tepatitlan.

Instituto Nacional de Estadística y Geografía [Inegi]. (2019). Población rural y urbana. cuéntame. Recuperado de http://cuentame.inegi.org.mx/poblacion/rur_urb.aspx?tema=P. 


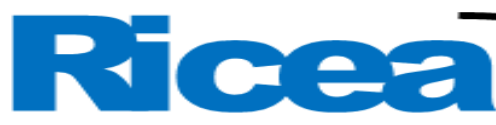

Los Gordos. (2020)
REVISTA IBEROAMERICANA DE CONTADURÍA, ECONOMÍA Y ADMINISTRACIÓN

ISSN = $2007-9907$ http://www.losgordosrestaurant.com/inicio.html.

Martínez, M. (2016). Población y aspectos sociodemográficos de Tepatitlán de Morelos, Jalisco. En Cruz, L. (coord.), Salud y sociedad en Tepatitlán, Jalisco (pp. 215-227). México: Trauco Editorial.

Méndez, M. (2005). Contradicción, complementariedad e hibridación en las relaciones entre lo rural y lo urbano. En Ávila, H. (coord.), Lo urbano-rural, ¿nuevas expresiones territoriales? (pp. 87-122). Cuernavaca, México: Universidad Nacional Autónoma de México.

Palomar. C. (2005). El orden discursivo de género en Los Altos de Jalisco. Guadalajara, México: Universidad de Guadalajara.

Pradilla, E. (2002). Campo y ciudad en el capitalismo actual. Ciudades, (54), 3-8.

Ramírez, B. (2005). Miradas y posturas frente a la ciudad y el campo. En Ávila, H. (coord.), Lo urbano-rural, ¿nuevas expresiones territoriales? (61-85). Cuernavaca, México: Universidad Nacional Autónoma de México.

Torres, G., Madrid de Zito, L. y Santoni, M. (2004). El alimento, la cocina étnica, la gastronomía nacional. Elemento patrimonial y un referente de la identidad cultural. Scripta Ethnologica, (26), 55-66. Recuperado de http://www.redalyc.org/articulo.oa?id=14802603. 